\title{
Anxiety Level Among Patients Undergoing Ultrasound Examination in Ghana
}

\author{
William Kwadwo Antwi, Kofi Adesi Kyei, James Newlife Gawugah, Samuel Yaw Opoku, \\ Esther Ihuoma Ogbuokiri
}

Department of Radiography, School of Biomedical and Allied Health Sciences, University of Ghana, Korle-Bu, Accra, Ghana

Email address:

adesco41@hotmail.com (K. A. Kyei), kakyei@chs.ug.edu.gh (K. A. Kyei)

\section{To cite this article:}

William Kwadwo Antwi, Kofi Adesi Kyei, James Newlife Gawugah, Samuel Yaw Opoku, Esther Ihuoma Ogbuokiri. Anxiety Level Among Patients Undergoing Ultrasound Examination in Ghana. International Journal of Medical Imaging. Vol. 3, No. 1, 2015, pp. 6-10. doi: $10.11648 /$ j.jimi.20150301.12

\begin{abstract}
Background: Anxiety is a feeling of tension associated with a sense of threat of danger when the source is unknown. Anxiety disorders are often associated with common age related medical and chronic conditions such asthma, thyroid disease, coronary artery disease, dementia and sensory loss. Most diagnostic medical imaging has been seen to be associated with some level of anxiety. Aim: The aim was to investigate and compare the anxiety levels of women undergoing ultrasound examination. Methods: A quantitative method with descriptive design was used for the study using closed-ended and few open-ended questionnaires with 100 participants. Data collected were analyzed using the Statistical and Packages for Social Sciences Version 20.0 and Microsoft excel. Result: The result showed that there was no difference between the pre and post procedural anxiety in the patient and one of the major causes of anxiety was lack pre-procedural information and fear of the outcomes of the examination being done. Conclusion: It was concluded that the patients feel anxious before and after an ultrasound examination.
\end{abstract}

Keywords: Anxiety, Ultrasound, Anxiety Disorders, Outcomes

\section{Background}

Anxiety is defined as a normal reaction to stress which helps one deal with tense situations, at the office, studies, when preparing for an interview and in many other situations [1]. Ultrasound is a radiological diagnostic procedure which involves the use of non -ionizing radiation. It uses high frequency sound-waves to produce relatively precise images of structures within the body. It is a relatively superior imaging modality which allows for dynamic images whereby patients can be examined either lying or sitting on a padded bed and it is relatively inexpensive.

According to Chojnak, et al [2] the prevalence of anxiety is high among patients awaiting diagnostic procedures and thus patients in the waiting room should be screened for anxiety. The increasing availability and capabilities of the various imaging modalities to improve medical diagnoses and prognosis have dramatically increased the number of procedures performed worldwide. Thus, many patients are undergoing imaging procedures for an ever-widening spectrum of indications. For certain patients that undergo these procedures, the experience may cause great emotional distress [3]. Studies by Jangland, et al [4] found that among patients who complained about care and increased anxiety, insufficient information, inadequate respect and inadequate empathy were major contributory factors and thus reducing their confidence in the health care system.

Research shows that the prevalence of anxiety is high among patients awaiting diagnostic procedures [2], and therefore the need to find out the level and at what point of their examination that patients experience anxiety. Issues of anxiety do not only affect the patients but also the medical team in terms of producing accurate diagnostic results. The adverse outcomes as a result of patient's anxiety include unintentional exacerbation of patient distress, a compromise in the quality and thus, the diagnostic aspects of the imaging study and decreased efficiency of the imaging facility due to delayed, prematurely terminated or cancelled examinations [3].

In Ghana little has being done in assessing both preprocedural and post-procedural anxiety in women coming for 
ultrasound examination hence the need to conduct the study to find out the means to either prevent or reduce such anxiety in patients in order to maintain quality services and results. The investigation of the cause of anxiety may be important not only to enable better understanding of patients experience but also for a successful implementation of anxiety management interventions. The ability of radiologists and radiographers to detect patient distress at the earliest possible time and to discover the source of the distress could help in providing the appropriate intervention which could greatly improve patient comfort, quality of imaging studies and efficiency of the facility [3]. The study was to compare the anxiety level of women undergoing ultrasound in a Teaching Hospital in Ghana.

\section{Methodology}

The study was a descriptive and was conducted for females undergoing ultrasound at the unit of the hospital. After a review of patients records from the hospital a total number of one 100 patients were recruited for the study. In determination of the sample size in the hospital this formula was used;

$\mathrm{N}=\mathrm{Z}^{2}(\mathrm{P} \times Q) / E^{2}$ where, $\mathrm{N}=$ Sample size, $\mathrm{Z}^{2}=$ The 95 percentile of the $\mathrm{Z}$ score, $\mathrm{P}=$ Prevalence, $\mathrm{Q}=1-\mathrm{P}, \mathrm{E}=$ Error

The population of patients was 250 and those for ultrasounds were within a month was 45 , hence, $\mathrm{P}$ was $45 / 250=0.18$ and $\mathrm{Q}$ is $1-\mathrm{P}, \mathrm{N}=1.96^{2}(0.18 \times 0.82) 0.05^{2}=100$

A convenient sampling method was employed to select all female patients between the ages of 18 and 60 who attended clinic for the procedures and consented to participate in the research within four weeks. Patients below age 18 and above age 60 as well as those who refused to consent were excluded. A questionnaire was administered to the patient before and after the ultrasound procedure. The questionnaire comprised of both open and closed ended question and consisted of demographic information, re-procedural and post- procedural information.

Data obtained were analyzed using and Statistical Package Social Sciences version 20.0 and Microsoft Excel. Results were represented in graphs, tables and charts. Chi square test were also used to show associations. All statistical tests were conducted as two-sided, and declared significant for $\mathrm{p}$-value $<0.05$. Approval for the study was obtained from the research ethics committee of a higher education institution. The ethics approval was supported by written permission for the study to be conducted at the study site. All study participants gave informed consent prior to the commencement of the study.

\section{Result}

100 participants responded to the survey, lillustrated that most of the respondent got their information from the referring clinician $(50 \%)$. This Fig indicated that majority of the patients $(52 \%)$ affirmed that they had done an ultrasound examination before.
Table 1. Association between anxiety and age of patients

\begin{tabular}{lllllll}
\hline $\begin{array}{l}\text { Age } \\
\text { Range }\end{array}$ & $\begin{array}{l}\text { Not } \\
\text { anxious }\end{array}$ & Anxious & $\begin{array}{l}\text { Very } \\
\text { anxious }\end{array}$ & $\begin{array}{l}\text { Extremely } \\
\text { anxious }\end{array}$ & $\mathbf{X}^{\mathbf{2}}$ & P-value \\
\hline $20-30$ & 6 & 15 & 4 & 0 & 16.061 & 0.066 \\
$31-40$ & 13 & 14 & 4 & 0 & & \\
$41-50$ & 16 & 11 & 5 & 0 & & \\
$51-60$ & 1 & 7 & 3 & 0 & & \\
Total & 36 & 47 & 16 & & & \\
\hline
\end{tabular}

Table 1 shows that there is no assiociation between the age and their anxietylevels ( $p$-value $>0.05)$

Table 2. Association between anxiety and level of education

\begin{tabular}{lllllll}
\hline $\begin{array}{l}\text { Educational } \\
\text { level }\end{array}$ & $\begin{array}{l}\text { Not } \\
\text { anxious }\end{array}$ & Anxious & $\begin{array}{l}\text { Very } \\
\text { anxious }\end{array}$ & $\begin{array}{l}\text { Extremely } \\
\text { anxious }\end{array}$ & $\mathbf{X}^{\mathbf{2}}$ & $\begin{array}{l}\text { P- } \\
\text { value }\end{array}$ \\
\hline Primary & 11 & 7 & 0 & 0 & 12.866 & 0.169 \\
Secondary & 8 & 18 & 5 & 0 & & \\
Tertiary & 8 & 7 & 6 & 0 & & \\
Others & 9 & 15 & 5 & 0 & & \\
Total & 36 & 47 & 16 & & & \\
\hline
\end{tabular}

This table shows that there is no association between the level of education with the anxiety level ( $p$-value $>0.05)$.

Table 3. Association between anxiety and pre-procedural knowledge

\begin{tabular}{lllllll}
\hline $\begin{array}{l}\text { Pre- } \\
\text { procedural } \\
\text { information }\end{array}$ & $\begin{array}{l}\text { Not } \\
\text { anxious }\end{array}$ & Anxious & $\begin{array}{l}\text { Very } \\
\text { anxious }\end{array}$ & $\begin{array}{l}\text { Extremely } \\
\text { anxious }\end{array}$ & $\mathbf{X}^{\mathbf{2}}$ & $\begin{array}{l}\text { P } \\
\text { value }\end{array}$ \\
\hline Yes & 30 & 36 & 7 & 0 & 12.435 & 0.006 \\
No & 6 & 10 & 9 & 1 & & \\
Total & 36 & 47 & 16 & 1 & & \\
\hline
\end{tabular}

Table 3 shows that there is an association between the patients anxiety and their prior knowledge of the examination $(p$-value $<0.05)$

Table 4. Association between anxiety and the waiting time

\begin{tabular}{lllllll}
\hline $\begin{array}{l}\text { Waiting } \\
\text { time }\end{array}$ & $\begin{array}{l}\text { Not } \\
\text { anxious }\end{array}$ & Anxious & $\begin{array}{l}\text { Very } \\
\text { anxious }\end{array}$ & $\begin{array}{l}\text { Extremely } \\
\text { anxious }\end{array}$ & $\mathbf{X}^{2}$ & P-value \\
\hline$<30$ mins & 11 & 7 & 0 & 0 & 14.704 & 0.99 \\
31-60mins & 8 & 18 & 5 & 0 & & \\
$1-2 \mathrm{hrs}$ & 8 & 7 & 6 & 0 & & \\
Over 2hrs & 9 & 15 & 5 & 0 & & \\
Total & 36 & 47 & 16 & & & \\
\hline
\end{tabular}

Table 4 shows that there is no association between the patients anxiety level and their waiting time ( $p$ value $>0.05)$

Table 5. Association between anxiety and patient's satisfaction

\begin{tabular}{lllll}
\hline Anxiety levels & Satisfied & Not satisfied & $\mathbf{X}^{2}$ values & $\boldsymbol{p}$-values \\
\hline Not anxious & 21 & 4 & 7.058 & 0.070 \\
Anxious & 32 & 19 & & \\
Very anxious & 4 & 6 & & \\
$\begin{array}{l}\text { Extremely } \\
\text { anxious }\end{array}$ & 3 & 1 & & \\
Total & 60 & 30 & & \\
\hline
\end{tabular}

Table 5. shows that there is no association between the anxiety and patients satisfaction ( $p$-value $>0.05$ ) 


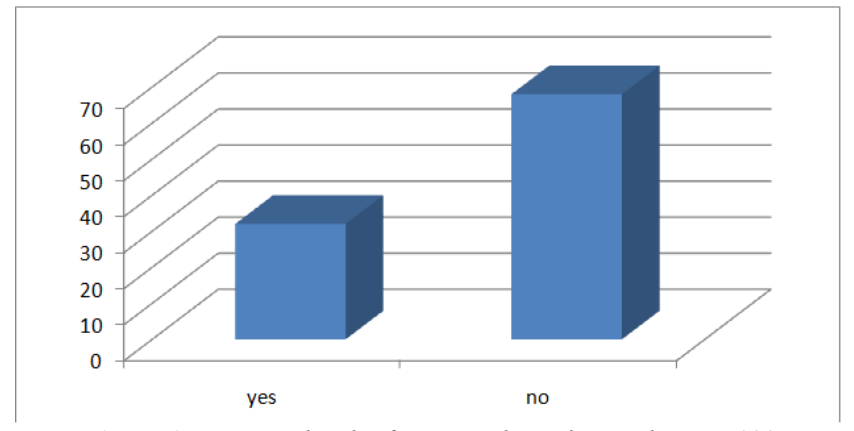

Figure 1. Preprocedural information by radiographers $n=100$

Figure 1 indicates that most of the patients did not receive pre-procedural information from their radiographers $(68 \%)$.

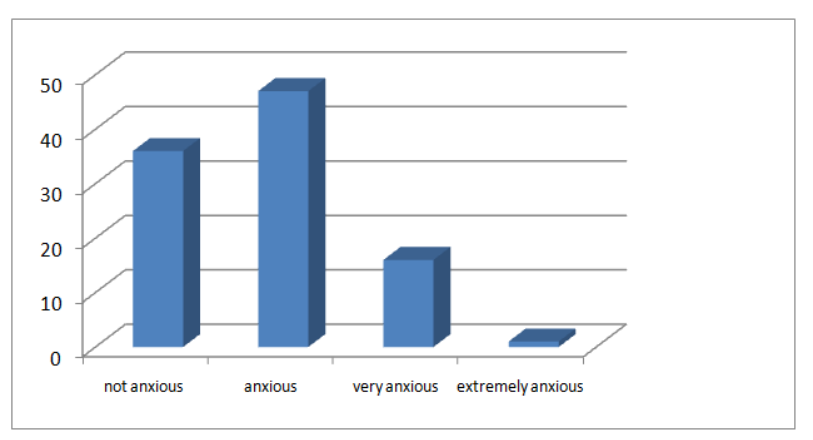

Figure 2. Rating of anxiety levels before the examination, $n=100$

Figure 2 shows that $47 \%$ indicated to have being anxious before the examination

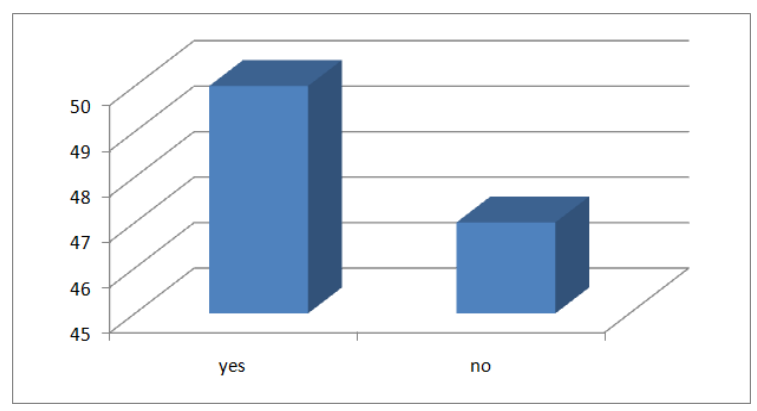

Figure 3. Anxiety due to outcome of the examination, $n=100$

Figure 3 indicates that majority of the respondent were anxious due to the outcome of the respondent.

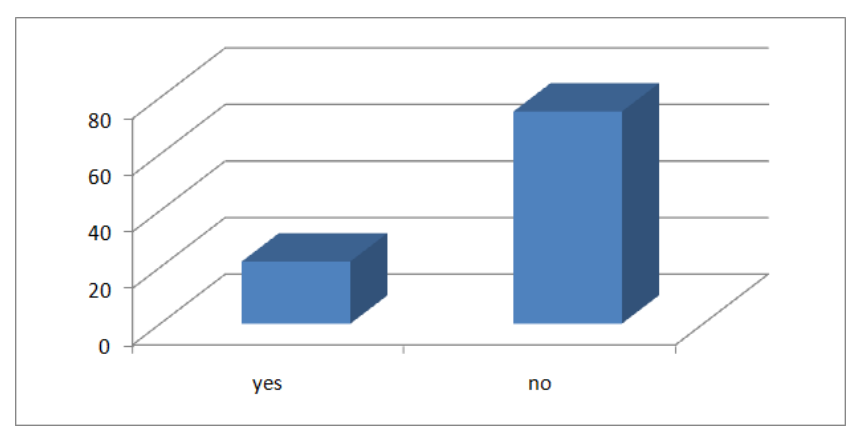

Figure 4. Pain or discomfort from the examination, $n=100$

Figure 4 indicates that $75 \%$ of the respondents were not anxious because of the pain or discomfort during the examination.

The majority of the patients were willing to undergo another ultrasound examination if asked to $(75 \%)$ and $59 \%$ of the respondent stated that the procedure was not long

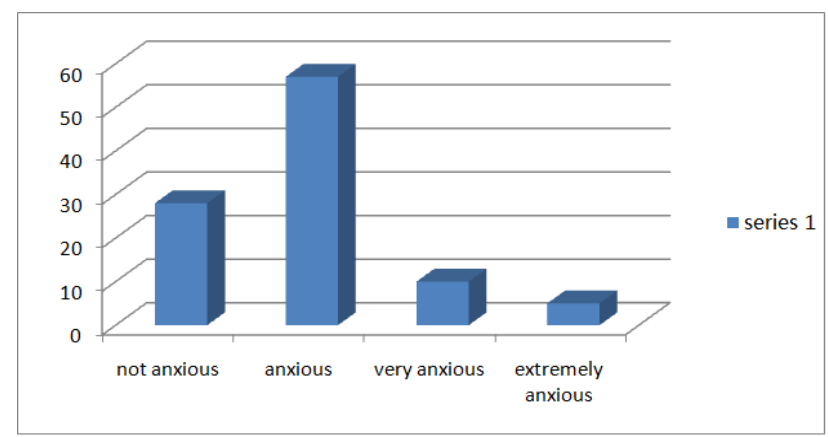

Figure 5. Post procedural anxiety, $n=100$

Figure 5 shows that majority of the respondents were still anxious after the examination $(57 \%)$.

\section{Comments from the Respondent}

Table 6. Comments from respondents

\begin{tabular}{ll}
\hline Responds from the respondent & Frequency (\%) \\
\hline $\begin{array}{l}\text { Patients should be given detailed prior explanation } \\
\text { of the procedure }\end{array}$ & 51 \\
$\begin{array}{l}\text { There should be proper interaction between staff } \\
\text { \&patients }\end{array}$ & 7 \\
$\begin{array}{l}\text { Patients should not spend so much time before they } \\
\text { are called }\end{array}$ & 16 \\
$\begin{array}{l}\text { The environment of the unit and waiting room } \\
\text { should be clean }\end{array}$ & 4 \\
$\begin{array}{l}\text { Patients should be reassures after the examination } \\
\text { Patients with special medical conditions should be } \\
\text { given special considerations }\end{array}$ & 6 \\
$\begin{array}{l}\text { Provision of proper directions to the ultrasound } \\
\text { room }\end{array}$ & 5 \\
\hline
\end{tabular}

\section{Discussion}

\subsection{Socio-Demographic Factors}

With respect to the participant socio-demographic status, majority of the respondents who came for the procedure were between the ages of 31-40years, but in relation to anxiety majority of the patients who were anxious were between the ages of 21-30years. Though literature indicates that anxiety may begin at childhood, other studies confirm that it may strongly manifest in the adolescent [1]. However there was no significant difference in the anxiety levels between the age groups of 21-30 and 31-40 years. As regards the educational level, most respondents had either secondary education, or with tertiary education, there was no association between the level of education and their anxiety level.

\subsection{Pre-Procedural Anxiety Levels}

Most patients visit the radiology department without much knowledge of the procedures they are referred to do [5], 
however in this study most of the respondents affirmed their knowledge of the ultrasound procedure before they came for it with majority receiving their source of information from their referring clinicians (Fig. 1). In spite of the participants having some prior knowledge of the procedure, they still felt anxious before the examination indicating that there is an association between the pre-procedural knowledge and the anxiety level ( $p$-value $<0.05$ contrary to results from literature reviewed by Gillen, Biley \& Allen [6] which concluded that pre- procedural knowledge of examination did not affect anxiety levels.

In the study most patients declared that they had not received any information from the health personnel prior the examination and also as indicated in Table 3 , most of the patients who had no prior information were anxious, this showed that when little or no information are given to the patients it creates worry hence increasing anxiety [7].The other patients who affirmed to have had receive knowledge and were still anxious maybe due their inability to absorb information given to them by their caregivers confirming the research carried out by Sarji et al, [8].

The majority of the patients waited for a period of 31-60 minutes, which seems to an indication that there was an association from the frequency between the patient waiting time and their anxious level however this association was not statistically significant ( $p$ value $>0.05$ ). This shows that patients' anxiety does not necessarily increase with the patients waiting time which contradicts the work of Nikil et $a l$, [9] that prolonged delay and waiting time give patients free scopes of imagination in turn lead to unnecessary increase in anxiety.

\subsection{Post Procedural Anxiety}

Findings show that after the procedures the majority of the patients were anxious and one major reason for their anxiety was due to outcome/findings of the examination (Fig. 5) in support of Detraux et al, [10] and Christaine et al,[11] who stated that major reasons why women are anxious during and after an ultrasound examination is because of the fear of the outcome of the examination. Distressor anxiety is not determined by the invasiveness or pain of the procedure as argued by Kowaleek et al [12] which supports the findings of this study. Most of the patients were not anxious about the pain or discomfort they may go through but rather, are primarily concerned about their problems and outcomes (Christaine et al,) [11]. These findings contradicts a previous work by Detraux et al,[10] whose study found that transvaginal ultrasound cause and trigger anxiety and posttraumatic stress symptoms among these patients.

\subsection{Effects of Anxiety on Patient's Satisfaction}

The majority of the respondents were satisfied with the ultrasound procedures as shown in Table 5, however there was no association between the anxiety level and the patients satisfaction $(p-$ value $>0.05)$. Thus the patients were though anxious it did not affect their satisfaction. This could be related to the fact that most patient from the study indicated that they would not hesitate if asked to undergo the procedure again in contradiction with the study by Detraux et al [10]. The patients' satisfaction could be, the healthcare personnel, related to them in a friendly manner and also they found the imaging room to be comfortable.

\subsection{Measures to Minimizing Anxiety from Respondent}

Various comments made by the patients in the quest to minimize anxiety were; detailed explanation of procedures prior to its commencement, proper interaction between staff and patients, reassurance of patients after procedures, shorter waiting time, conducive environment and preferential treatment for those with other special medical conditions which in agreement with Jangland et al [4] previous work all of which boost up confidence in the health care system.

\section{Conclusion}

The main causes of the anxiety were due to the outcomes and lack of detailed explanation of the procedure to the patients. The need for patient reassurance from the staff after the examination was found to be paramount in patient satisfaction. Anxiety did not affect the patient's satisfaction because most of the patients showed readiness to undergo another ultrasound examination when the need be. There was no statistical association between the waiting time and the anxiety level, the longer the patients waited did not affect their anxiety level and vice versa. From the patients' perspective, proper explanation of procedures, care by the health professional and attempt to reduce the waiting time will help to reduce their anxiety. Preferential treatment of patients with special medical conditions and ensuring that the environment is conducive for their management were paramount to patients.

\section{Recommendation}

With regards to the outcome of the research, it is recommended that

1. Seminars and workshops should be organized for staffs in the department to upgrade their knowledge and practice in effective patient management so that their interpersonal skills

2. Measures for signs board and effective direction to the department should be made to enable patients locate the departments without stress.

3. Caregiver should demonstrate greater sense of professionalism; they should show a sense of concern to enable patients to be more relaxed and less anxious.

4. Professionals should be able to communicate effectively and nicely to increase confidence of the patients and hence reduce anxiety.

5. Educating the nation about the imaging department as well as educating them about their rights as patients so that they can feel more confidence in the department. 


\section{References}

[1] Miller, J. L., (2010). Forms of Anxiety Disorder. Retrieved from: http://ezinearticles. com/forms of anxiety.

[2] Chojniak R, Yu L and Barba M.A et al (2011). Prevalence and anxiety in patient's awaiting procedures in Brazil; Psychology, 20:1242-1245.

[3] Martin, P, Bishop, A, Poon, L and Johnson,M.A (2006).Influence of Personality and Health behavior on fatigue in late and very late life. Journal of Gerontology: Series B;Psychological sciences and social sciences ,61(3),161-165

[4] Jangland E,Gunungberg L ,Carson M.(2006). Patients and Relatives complaints about encounters and communication in healthcare: Evidence for quality improvement .Patient education counseling; 75(2):199-204.

[5] Ahmed, S. M., and Lemkau, J. P., (2007) Psychosocial influences on health. In: Rakel RE, ed. Textbook of Family Medicine. 7th ed. Philadelphia, Pa: Saunders Elsevier; chapter 4.

[6] Gillen E, Biley F \& Allen D. (2008). Effect of music listening on adult patient's preprocedural state anxiety in hospital: International Journal of Evidence Based health; 6:24-49.

[7] Kleanthi G, Katisna L, Georgois D, Stavros J, Aris A. (2008).Women perception of information and experiences of Nuchal Transluency Screening in Greece. Fetal Diagnosis therapy; 24:86-91.

[8] Sarji S. A., Abdullah B.J, \& Kumar G. (1998). Failed magnetic resonance imaging examination due to claustrophobia: Australas Radiol; 42:293.

[9] Nikila A, Rydstroem H, Kallen B, \& Jorgensen C. (2006). Ultrasound screening for fetal anomalities in southern Sweden; a population-based study: Acta obstetric Gynecology Scand; 85(6):688-693.

[10] Detraux J.J, Gallot -de Vrres F, Vanden Eynde .S, Courtois A, \& Desmet A. (1998). Psychological impact of the announcement of a fetal abnormality on pregnant women and on professional: Ann NY Acad Sci : 18(847):210-219

[11] Christine J, Berbaum K, Berbaum M. \& Lang E. (2005). Pain and anxiety during interventional radiologic procedure: Effects of patients state anxiety at baseline and modulation by normapharmalogic analgesia adjunts; Journal of vascular and interventional Radiology;16(2);1585-1592.

[12] Kowaleek I, Mulhoff A, Bachmann S \& Gembruch U. (2002). Depressive reaction and stress related to prenatal medicine procedures: Ultrasound Obstetric Gynecology;19:18-23. 